\title{
THE IMPACT AND IMPORTANCE OF FABRIC IMAGE PREPROCESSING FOR THE NEW METHOD OF INDIVIDUAL INTER-THREAD PORES DETECTION
}

\author{
Magdalena Owczarek* \\ Institute of Architecture of Textiles, Faculty of Material Technologies and Textile Design, Lodz University of Technology, 116 Zeromskiego Street, \\ Building A33, 90924 Lodz, Poland \\ *Corresponding author. Email: magdalena.owczarek@p.lodz.pl
}

\begin{abstract}
:
The paper describes the impact and importance of preprocessing methods of fabric image for detection of interthread pores (ITP), which is a new method of individual ITP identification. The aim of this experiment is to identify precisely every individual ITP of fabric structure by using optimal preprocessing algorithm for further quantitative, morphometric structural analysis of specialized fabrics (barriers, industrial filters, composites, others) in context of air permeability, flow resistance, UV radiation, viruses penetration, thermal comfort by estimation fabric porosity, especially macroporosity parameters and cover factor. The correct identification of individual ITP depends on the acquisition method and the preprocessing algorithm. It was conducted by analyzing the adaptation of digital image preprocessing methods for two structures of plain weave fabric in two magnification zooms, 1.25 and 0.8. Preprocessing operations were performed in the area of spatial operations of the image. The optimal preprocessing algorithm includes low-pass filtering, histogram equalization, nonlinear filtering, thresholding, and morphological operation. This algorithm was selected based on the factors developed by the author (ITP detection, RID factor-a difference between the real and model ITP areas) which rely on the ITP size, shape, and location. The graphic view of the ITP contour position on the fabric image is a verification element in the optimal preprocessing algorithm. The presented results of the air permeability of two different plain weave structures confirm the need to optimize the algorithm of pre-image processing methods to precisely detect each individual ITP in the fabric image.
\end{abstract}

\section{Keywords:}

Computer image analysis; preprocessing; inter-thread pore; fabric structure; porosity; macroporosity; cover factor; air permeability; detection

\section{Introduction}

The development of the modern industrial civilization means heavy demand for textile products and here particularly to provide an effective barrier to flow, passage or a permeation of liquids, gases, air, radiation of different origin and the bodies of different sizes. In this type of product, the structure regularity and its accurate identification have a decisive impact on the product quality, especially in individual inter-thread pores (ITP) identification.

The methods of analyzing the structures used in this area should be approached with great care, for example for filtering applications, pore size influences the performance of the filter. Research shows that inter-thread pore is presented in a variety of contexts: air permeability of woven fabrics [1-5], flow resistance [6, 7], UV radiation [8], thermal comfort by estimation of porosity [9], macroporosity parameters [10] or fabric cover factor $[1,11,12]$. The publications demonstrate the significant influence of structure parameters, including porosity especially macroporosity, on the filtering properties of these structures. The porosity is defined as a physical characteristic of woven fabric, which is the portion of air volume in percentage to the total volume of fabric. The porosity of woven fabrics is usually divided into two types, i.e., the microporosity caused by the void spaces among fibers in threads and the macroporosity, which is a consequence of the void spaces among threads [2]. The macroporosity, which includes information about every individual ITP, is most important for the air permeability.

According to the publications, ITP were analyzed by considering all flat area in the fabric image as the average value. In this research, the importance of fabric image preprocessing in the detection of individual ITP is presented. It is a new concept to identify each ITP in the image of fabric structures. The research is based on the individual ITP identification method used in morphometrical structural analysis in woven fabrics as shown in an article. The ITP parameters were described in three aspects: size, shape, and location in the fabric structure [13].

Digital image analysis of the fabric structure began in the 1980 s. Many studies have shown that over $90 \%$ of the issues in computer image analysis are associated with the anisotropic property of textiles. Textile objects are characterized with anisotropy in the structure, surface, color, pattern, and absorption of light. These are the main elements that need to be adequately addressed when the desired information is obtained from the image. 
The acquisition methods, for assessing textiles, depending on the needs, are based on the use of a scanner, microscope with a CCD camera or a digital camera with lens. The scanner guarantees stable acquisition parameters [7, 14]. It does not allow adaptation of the image to specified magnification and features smaller than 0.042 [mm] will not be detected [13]. In most ITP analysis, CCD cameras with a microscope are used $[1-3,10-13]$.

Different studies used different magnifications of fabric images, and thus different ITP values, for example, 322 ITP, were corresponding to $23 \times 14$ threads in image, which equates to approximately $5.5 \times 4.2$ [mm] of fabric [1], or between 50 and 100 ITP in images [10], or near 90 ITP, $9 \times 8$ threads, $2.6 \times 3.4$ $[\mathrm{mm}]$ linear field size in every image [11, 12]. If we use a larger image magnification, we will obtain the greater detection accuracy and accuracy of the size, shape and location of all ITPs in the fabric image. If the test is to focus on only a general, estimated assessment of macroporosity, then the magnification is not of greatest importance.

In this research the new approach to individual ITP analysis in the fabric image was applied and higher fabric image magnification is used. For better ITP detection in each fabric image, only about 28-36 ITPs were observed, which corresponds to $8 \times 5$ threads and $3 \times 3$ [mm] linear field size for a sample of plain weave fabric.

Secondly, in the research $[3,10]$ macroporosity parameters were calculated from global size distribution of pore density. In this study and as presented in this article, the macroporosity parameters are calculated from every individual ITP. This new approach to ITP analysis allows identifying the size, shape and location of each individual ITP [13]. Therefore, in this case, it is crucial to develop new parameters of the ITP detection and accuracy (RID factor)-as the criterion in the selection of the optimal fabric image preprocessing algorithm.

The main problem of ITP identification in image analysis is the misclassification of pixels, which were close to yarn edges which is the ITP boundary line, resulting in, among other things, the image noise [3, 11]. Earlier our research [15] showed the preprocessing method can not only correct the image from the noise but can also change the information in the image. The preprocessing methods on artificial fabric images with different noise label (from $5 \%$ to $80 \%$ ) were verified. The desired results were obtained in low-pass filtration, median filtration, histogram equalization, and nonlinear filters. Low-pass filtration effectively removes noise up to a level of $20 \%$. In the statistical filtration-the median filter does not get a blurring effect such as in low pass filters, but induces adverse hyperplasia of the ITP areas. The nonlinear filtration-square and cubic functions for the images up to $40 \%$ noise-decreases the error of further analysis to zero. Different studies used a range of methods for the noise removal, for example, in articles $[16,17]$ only a median filter was used and in article [18], image brightness histogram equalization is used. It is also verified [15] that image brightness histogram equalizations for up to $50 \%$ disturbance can reduce the noise to zero. Therefore, using the various types of filters for image preprocessing can improve, but also deteriorate the results of the further morphometrical analysis of the image elements. Some authors have used two types of operations from preprocessing methods. In the article [1], the image preprocessing Gaussian filtering and histogram equalization were used to minimize noise and enhance contrast.

This article concentrates on building an optimal algorithm for image preprocessing of fabrics with plain weave, taking into account image acquisition parameters. The criteria of optimal algorithm were the two factors as stated by the author: ITP detection; RID factor-a difference between the real and model ITP areas. They rely on the ITP size, shape, and location. The optimal algorithm corresponds to the visualization of ITP boundary line on the fabric image. The aim of this experiment is identifying precisely every individual element ITP, their surface areas boundaries, for further quantitative and morphometric structural analysis [13] of specialized fabrics in context of air permeability, flow resistance, UV radiation, viruses penetration and fabric macroporosity or cover factor. This experiment and example of comparison of air permeability results were given for two structures of the woven plain fabric. These structures were differentiated by the grouping of warp threads.

\section{Experimental Methodologies and Devices}

\subsection{Sample preparation}

The analysis was carried out on the fabric structure of the plain weave. This material was chosen due to the filtration application. Selected parameters of the fabric and component threads are given in Table 1 and visualization in Figure 1. The
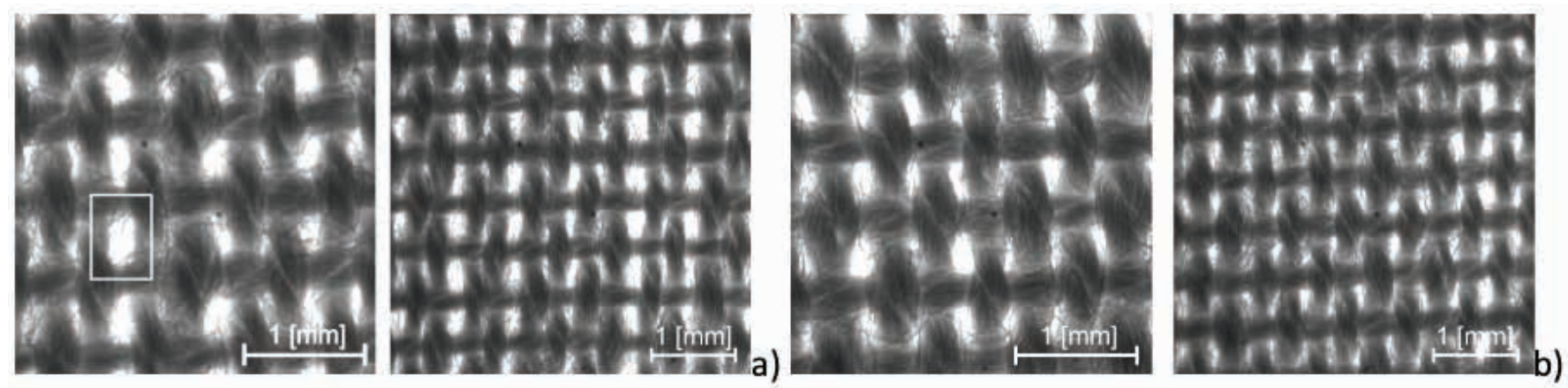

Figure 1. Images of experimental plain weave fabric structures with two image magnifications: zoom $1.25=3 \times 3$ [mm²] and zoom $0.8=5 \times 5$ [mm²]: (a) P1_1.25, P1_0.8_-plain weave fabric with grouped structure (b) P2_1.25, P2_0.8_plain weave fabric with ungrouped structure 
Table 1. Measured properties of fabrics $\mathrm{P} 1, \mathrm{P} 2$, and threads

\begin{tabular}{|c|c|}
\hline Plain fabrics parameters & Plain fabrics P1, P2 \\
\hline Density of warp $g_{\text {warp }}[$ threads/dm] & 230 \\
\hline Density of weft $g_{\text {weft }}[$ threads/dm] & 130 \\
\hline Threads & $20[$ tex $] \times 2$ \\
\hline Linear density of warp [tex] & 45 \\
\hline Linear density of weft [tex] & 36 \\
\hline Warp diameter $\mathrm{d}_{\text {warp }}[\mathrm{mm}]$ & 0.38 \\
\hline Weft diameter $\mathrm{d}_{\text {weft }}[\mathrm{mm}]$ & 0.47 \\
\hline Hairiness of thread [-] by USTER STATISTIC & 7.31 \\
\hline
\end{tabular}

structure of the plain weave, in principle, should be regular, but there is a grouping of warps that disturbs this structure and filtration properties. In plain fabric, we can have two kinds of structure, which can have either regular distance or irregular distance between the threads as presented in Figure 1a. These structures differentiated the degree of grouping of warps. That is why the identification of individual ITP is significant, which will help to assess the regularity of the fabric structure and, consequently, the air permeability ability. The criterion of the preprocessing is the detection of soft line border between threads without hairiness. The hairiness can have an impact on the border ITP detection, so in Table 1 this measurement is presented according to the USTER STATISTIC.

These two fabric structures have been evaluated for air permeability, Table 2. The analysis of air permeability was carried out in accordance with the PN-EN ISO 9237: 1998 standard. The measurement was performed at a pressure difference of 10 [daPa]. The data show that the air permeability parameters are at a similar level with a slightly higher value for $\mathrm{P} 1$ fabric. Greater air permeability is confirmed by the result of the structural analysis sum of ITP area in the image $\left(\Sigma \_\right.$A $\left.\left[\mathrm{mm}^{2}\right]\right)$. In contrast, the average size of the ITP area (A [ $\left.\left.\mathrm{mm}^{2}\right]\right)$ is the same for these fabrics. The only problematic indicator is increase in parameters of standard deviation and coefficient of variation of ITP area size for fabric P1 $\left(\sigma_{-} A\left[\mathrm{~mm}^{2}\right]\right.$ and

Table 2. The results of air permeability and the ITP structural analysis fabrics P1, P2, where AIR_R, o_AIR_R, [ $\left.\mathrm{dm}^{3} / \mathrm{min}\right]$ and cV_AIR_R[\%]air permeability parameters; $\Sigma_{-} \mathrm{A}\left[\mathrm{mm}^{2}\right]$ sum of ITP area in the image; $A, \sigma \_A\left[\mathrm{~mm}^{2}\right]$ and cV_A [\%] - average of ITP area

\begin{tabular}{|c|c|c|c|c|c|c|c|}
\hline \multirow{2}{*}{ 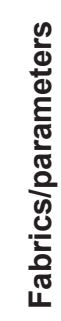 } & \multicolumn{3}{|c|}{ Air permeability } & \multicolumn{4}{|c|}{ Structural analysis } \\
\hline & 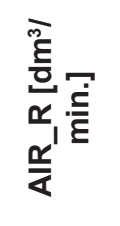 & 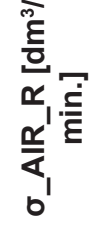 & 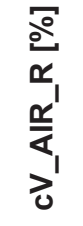 & 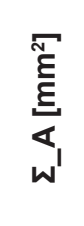 & 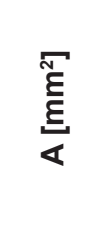 & 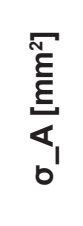 & 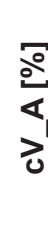 \\
\hline P1 & 882.16 & 33.77 & 3.83 & 0.91 & 0.032 & 0.03 & 89 \\
\hline P2 & 819.00 & 17.06 & 2.08 & 0.74 & 0.031 & 0.02 & 58 \\
\hline
\end{tabular}

cV_A[\%]). Therefore, a thorough structural analysis of individual ITP should be performed to be able to assess the size of the elements that these fabrics will be able to filter in the filtration process. In order to determine the exact information on the size of the individual ITP area in the image of the filtration fabric, it is necessary to carry out the appropriate acquisition process and the preprocessing algorithm. These processes have an impact on the result of morphometric analysis, so one should analyze the impact of these processes on the result of the detection and accuracy of ITP determination.

\subsection{The test stand}

The test stand consists of 4 modules of of image information processing in the digital image analysis system according to the literature [19], shown in Figure 2:

The first three modules determine the method of digital image recording, called Image Acquisition. The light energy distribution of a three-dimensional object is captured by the optical system and projected onto the photosensitive surface of the optoelectric transducer, e.g., camera CCD-4012A VideOTronic, PAL $(625 \times 570)$. An optical image is created in the two-dimensional space, which is the input signal for the A/D converter LFG 1024 and the video signal is the output. For the image to be analyzed by a digital device, an analogue format must be converted into a digital format. This process is called discretization and it consists of sampling and quantizing. Sampling is the process conversion of parameters into a matrix of points numbers $(1024 \times 1024)$, whereas quantization is the conversion of continuous brightness into luminance values (from 16 to 256) [19]. The next module covers the second phase of the image identification preparation (called identification and interpretation), which includes: preprocessing, segmentation, representation, and description. For image analysis, besides standard devices, two newly designed devices were used: (1) a table with the measurement area $30 \mathrm{~cm}^{2}$ and controlled/steered movement of the measurement area in two perpendicular directions and (2) copyright MagFABRIC software for image preprocessing and fabric structure analysis. 


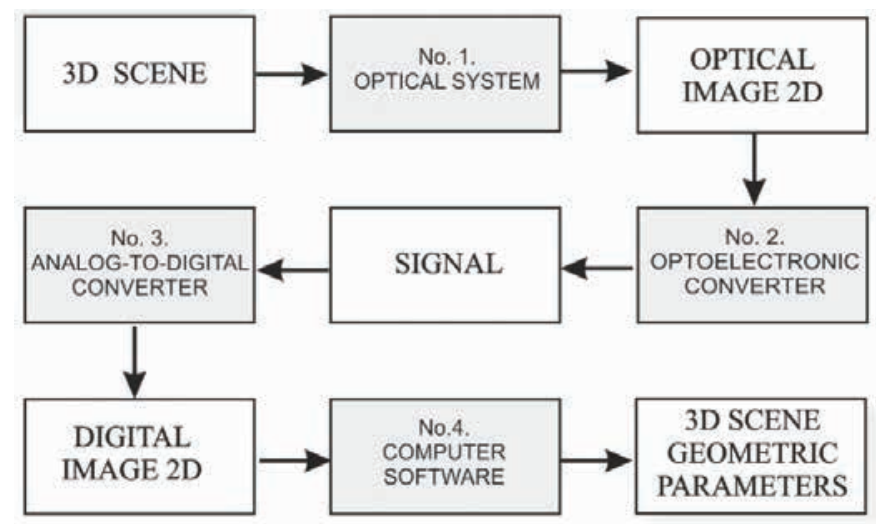

Figure 2. Diagram of image information processing in the digital image analysis system [19].

Hardware architecture consists of:

No. 1. OPTICAL SYSTEM—optical image formation module, which contains:

- $\quad$ stereoscopy microscope PZO Mst Zoom 1302

- $\quad$ backlight annular Olympus HIGHLIGHT 3100

- table with surface moving in two perpendicular directions

No. 2. OPTOELECTRONIC CONVERTER-module of optical image transformation to electric signal:

- $\quad$ camera CCD-4012 A VideOTronic, PAL (625 x 570)

No. 3. ANALOG-TO-DIGITAL CONVERTER—module of electric signal transformation to digital image:

- $\quad$ A/D converter LFG 1024 firm Logitex; (Frame Grabber with resolutions: 1024 x 1024, $1280 \times 1280,1536 \times 1536,1360 \times 1360$ )

No. 4. COMPUTER SOFTWARE-module of processing, analyzing, and visualization of information from the digital image:

- $\quad$ computer with author software MagFABRIC.

\subsection{Image acquisition}

At the stage of acquiring the image of the fabric, the backlight light was used-passing the light through the fabric by using the optical ring. The lighting equipment was installed at the bottom, perpendicular to the plane of the fabric at a distance of $10 \mathrm{~cm}$. This lighting provides identification of ITP in the fabric and regularity of lighting. The Olympus HIGHLIGHT 3100 lighting parameters are set to provide contrast between the threads and the ITPs. Procedures were developed in the copyright MagFABRIC software to measure and equalize brightness in individual parts of the image to ensure the regularity of this parameter (Figure 3).

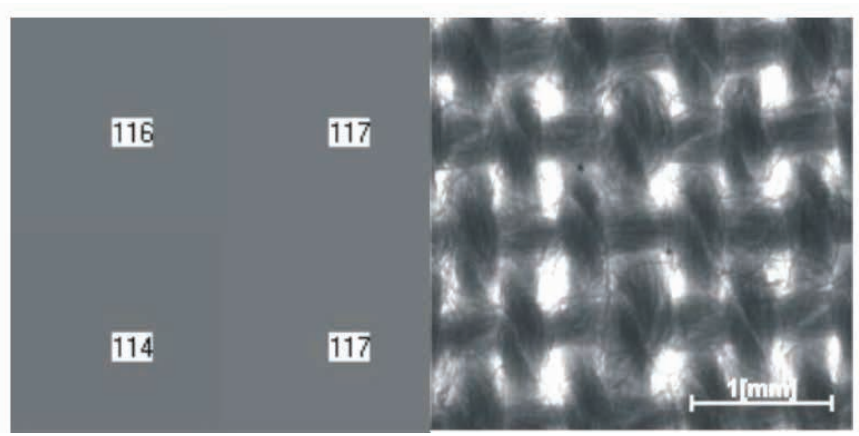

Figure 3. Fabrics acquisition lighting irregularity evaluation in the author MagFABRIC software
The image magnification was set on 1.25 and 0.8 zooms in the experiment. In the zoom 1.25, we observed max $7 \times 5$ threads, approximately 24-35 ITP and $3 \times 3$ [mm] of fabric. In the zoom 0.8, we observed 12 ' 7 threads, 66-84 ITP, $5 \times 5$ $\left[\mathrm{mm}^{2}\right]$, Figure 1. In other literature articles, such magnification values were used to analyze the ITP image, to give: 322 ITP [1], 50-100 ITP [10], near 90 ITP [11, 12]. The spatial resolution of the captured image was 1024 × 1024 pixels. Every image was monochromatic with 8 bpp (bit per pixel), 256 gray level.

\subsection{Image preprocessing}

The first stage of digital image analysis after the acquisition is image preprocessing. On the basis of literature [19-24], the image quality improvement methods or classifications were performed. It was divided into two stages: distortions correction after acquisition and image quality improvement. All procedures were prepared and verified by author with MagFABRIC software.

\subsubsection{Distortions correction after acquisition}

For distortion correction after the acquisition the procedures were prepared to identify:

- the radiometric distortions, due to irregular lighting and noise coming from the circuit transmitting an image signal,

- the geometric distortion due to the optics and electronics.

Radiometric distortions are evaluated on the basis of the regular brightness assessment in the areas of white and black images. The white identifies the distortion caused by light scattering (Figure 4a), meanwhile the black image identifies the distortion caused by the camera transmission (Figure 4b). The correction of radiometric distortions is carried out by means of adding, subtracting, or multiplying the subsequent image records. In our study, the difference is only on one level (255-254 white image, 13-14 black image) (Figure 4a,b).

For geometric distortions identification, geometrical patterns of various shapes and sizes in the range of 1 to $3\left[\mathrm{~mm}^{2}\right]$ were prepared. They were made using the technique of exposure on plastic film, in the positive and negative (using laser printer with resolution $300 \mathrm{dpi}$ ). (Figure 4c). The accuracy of the dimensions of the individual patterns was examined on the Mitutoyo projector at a magnification of $10 x$. The calculated accuracy was 0.001 [mm]. Furthermore the lack of square patterns in 5 scale magnification (zoom 0.6 -2.0) were used for acquisition and structural analysis: size and proportion of every element. The percentage value of the difference in width and height to the height of the square pattern in the increasing size scale was assessed. The result is illustrated by a decreasing error with the scale increase from $1.22 \%$ to $1.12 \%$. (Figure $4 \mathrm{c}$ and Table 3).

\subsubsection{Image quality improvement}

The use of filters for image preprocessing may lead to improvement or deterioration of further quantitative image 


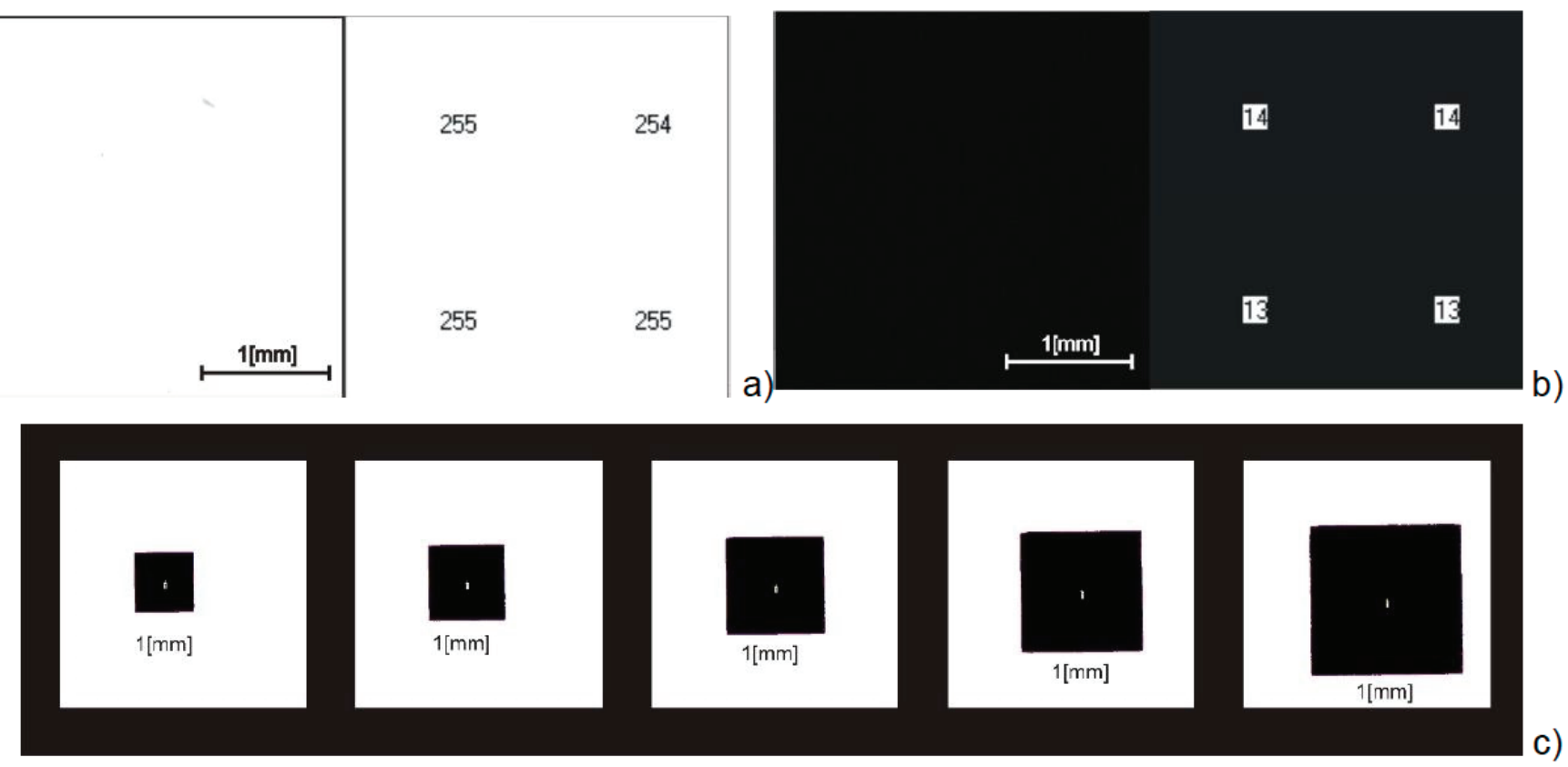

Figure 4. Distortion test: Radiometric: (a) a reference image "white," (b) "black" scene image. Geometric: (c) black square patterns in 5 scale magnification (image 1-5, zoom 0.62-2.0)

Table 3. Results of image analysis of black squares in 5 scales after the analysis in the author MagFABRIC software

\begin{tabular}{|c|c|c|c|c|}
\hline Image/(zoom) & Width [pix] & Height [pix] & (Width-height) /height*100 [\%] & Area [pix] \\
\hline $1(0.62)$ & 248 & 245 & 1.22 & 59,580 \\
\hline $2(0.8)$ & 318 & 314 & 1.27 & 97,918 \\
\hline $3(1.0)$ & 408 & 403 & 1.24 & 160,940 \\
\hline $4(1.25)$ & 507 & 501 & 1.20 & 248,440 \\
\hline $5(2.0)$ & 630 & 623 & 1.12 & 384,208 \\
\hline
\end{tabular}

Table 4. Juxtaposition of preprocessing methods, used to build algorithms for fabrics image analysis

\begin{tabular}{|c|c|c|}
\hline $\begin{array}{l}\text { Nonlinear filters }\left(\mathbf{x}^{2}\right) \\
\qquad\left(\mathbf{x}^{3}\right)\end{array}$ & $\begin{array}{l}\text { Low-pass filters Gauss (dp G } \\
\quad 3 \times 3 \text {, dp G } 5 \times 5 \text { ) }\end{array}$ & $\begin{array}{l}\text { Stretching the histogram brightness levels to the full range } \\
\qquad[0-255](\mathrm{h}[0-255])\end{array}$ \\
\hline $\begin{array}{c}g(i, j)=\left(f_{k}(i, j)\right)^{m} \\
m=2 \text { or } 3\end{array}$ & $\begin{array}{c}g(i, j)=\sum_{k=1}^{n} w_{k}(i, j) f_{k}(i, j) \\
\text { dp } \mathrm{G} 3 \times 3, \text { sum }=16 \\
\text { mask: }(1,2,1,2,4,2,1,2,1) \\
\text { dp } \mathrm{G} 5 \times 5, \text { sum }=76 \\
\text { mask: }(1,2,3,2,1,2,4,5,4,1 \\
3,5,6,5,3,2,4,5,4,2,1,2 \\
3,2,1)\end{array}$ & 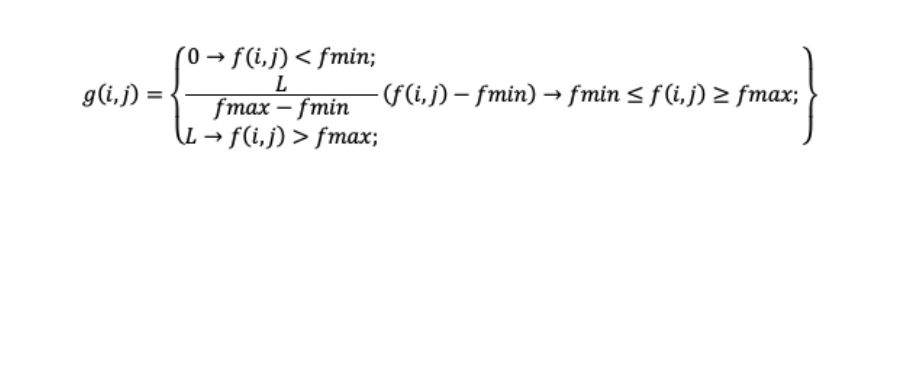 \\
\hline \multicolumn{2}{|c|}{$\begin{array}{c}\text { where } \\
f_{k}(i, j) \text {-value of kth pixel with coordinates }(i, j) \text { of the } \\
\text { original image, } \\
g(i, j) \text {-value of the pixel coordinates }(i, j) \text { of the resultant } \\
\text { image, } \\
\mathrm{w}_{\mathrm{k}}(i, j) \text {-weave mask-the weight of the } k \text { th pixel } \\
\text { environment }\end{array}$} & $\begin{array}{c}\text { where } \\
\begin{array}{c}L \text {-level of brightness } \\
g(i, j) \text {-value of the pixel with coordinates }(i, j) \text { of the resultant } \\
\text { image, }\end{array} \\
f(i, j) \text {-a value of a pixel with coordinates }(i, j) \text { of the original } \\
\text { image, }\end{array}$ \\
\hline
\end{tabular}


analysis. The filtering procedure based on spatial methods of image pixel conversion was carried out in the author's copyright MagFABRIC software. The methods verification was performed with the use of artificial images generated by computer [15] and real fabrics [25]. The correct execution of one or more filtering operations affects the segmentation, which means separating the objects from the background image.

In determining the optimal computer image preprocessing algorithm, the results of theoretical analysis from the artificially generated image, contained in the thesis [15] were taken into consideration. This experiment showed that for the noise elimination (artificially programmed "sand"), the following methods worked with positive results: stretching the brightness level of the histogram to the full range [0-255] or nonlinear filters: square $\left(x^{2}\right)$ and cubic $\left(x^{3}\right)$. These methods increase the image contrast and highlight the details of previously invisible bright elements and the images up to $40 \%$ disturbance, decreasing the error of further analysis to zero [15]. Despite the fact low-pass filters cause blurred edges, they improve the results by $1 \%$ in case of images with small noise-up to $20 \%$. When images are more disturbing, additional operations improving image quality should be performed [15]. In this experiment the following preprocessing methods were used: nonlinear filtration methods and low-pass filtering-Gaussian filter and histogram stretching (Table 4).

\subsection{Segmentation}

The Segmentation process is a very important procedure in image processing. The process is aimed at extracting the objects from the image after the filtering process. Universal algorithms application can lead to errors such as the creation of borders in the wrong place where they are not present in reality. If we use the same threshold value for every image, we will not get adequate border ITP detection. This is because each image of the fabric may have a different level of brightness, even if we ensure constant lighting conditions. Taking into consideration other studies [1, 11, 19-24], the author designed an automatic algorithm of segmentation and used it in MagFABRIC software. The automatic algorithm was based on two methods: region splitting and region-growing. These were based on Gauss and

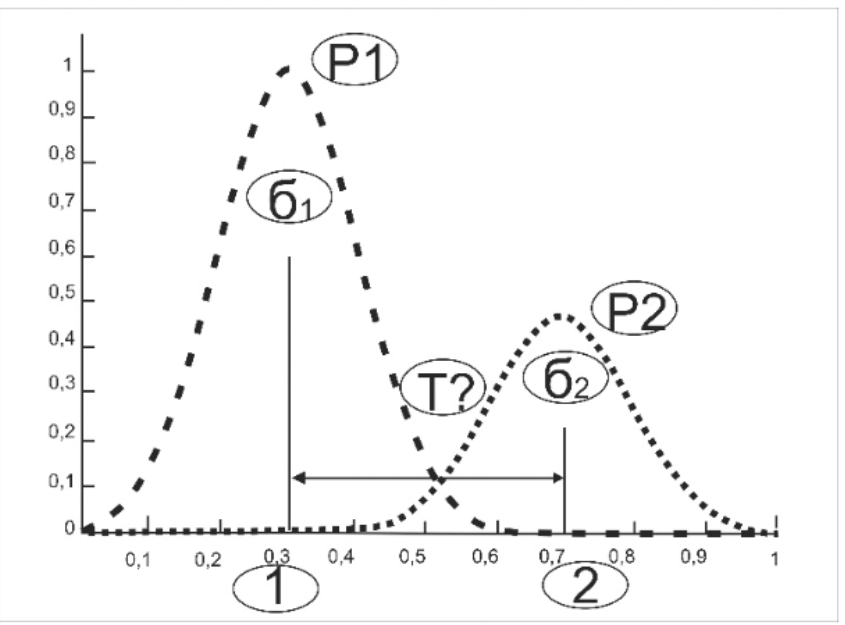

Poisson distributions in the image of background $p(x, y)$ and object $f(x, y)$ (Figure 5). Thresholding value $T$ was found from functions of:

$$
T=T(p(x, y), f(x, y))
$$

Allow the image containing areas with brightness levels centered on two mean values: object and background, each with a Gaussian $N(\mu, \sigma)$ distribution. These areas occur in shares $\mathrm{P} 1$ and $\mathrm{P} 2$ with:

$\mathrm{P} 1+\mathrm{P} 2=1$

Assume that $p_{1}(z)$ and $p_{2}(z)$ are the probability density of the normal distribution $N\left(\mu_{1}, \sigma_{1}\right), N\left(\mu_{2}, \sigma_{2}\right)$, respectively:

$$
\begin{aligned}
& p_{1}(z)=\frac{1}{\sigma_{1} \sqrt{2 \pi}} \cdot e^{-\frac{\left(z-\mu_{1}\right)^{2}}{2 \sigma_{1}^{2}}} \\
& p_{2}(z)=\frac{1}{\sigma_{2} \sqrt{2 \pi}} \cdot e^{-\frac{\left(z-\mu_{2}\right)^{2}}{2 \sigma_{2}^{2}}}
\end{aligned}
$$

where

$p_{1}(z)$-the image probability density belonging to the object and included in the background,

$p_{2}(z)$-image probability density belonging to the background and included in the object,

$\mu_{1}, \mu_{2}$-expected values for the first and second distribution,

$\sigma_{1}^{2}, \sigma_{2}^{2}$-variance for the first and second distribution.

The final threshold value:

$$
t=\frac{\left(\mu_{1}+\mu_{2}\right)}{2}+\frac{\sigma^{2}}{\left(\mu_{1}-\mu_{2}\right)} \ln \frac{P_{2}}{P_{1}}
$$

\subsection{The morphological operations}

In the segmentation process, it is necessary to improve the binary image which is crucial for further quantitative analysis. The morphological operations tested in this experiment:

closing $=1 \mathrm{x}$ dilatation $+1 \mathrm{x}$ erosion:, $\mathrm{A} \bullet \mathrm{B}=(\mathrm{A} \oplus \mathrm{B}) \ominus \mathrm{B}$

opening $=1 \mathrm{x}$ erosion $+1 \mathrm{x}$ dilatation: $A \circ \mathrm{B}=(\mathrm{A} \ominus \mathrm{B}) \oplus \mathrm{B}$

where

$$
\begin{aligned}
& \text { erosion: } f^{\prime}(x, y)=\min _{x_{1}, y_{1} \in b(x, y)}\left(f\left(x_{1}, y_{1}\right)\right) \text {, structural element: }(1,1,1,1,1,1,1,1,1) \\
& \text { dilatation: } f^{\prime}(x, y)=\max _{x_{1}, y_{1} \in b(x, y)}\left(f\left(x_{1}, y_{1}\right)\right) \text {, structural element: }(x, x, x, x, 0, x, x, x, x)
\end{aligned}
$$

Figure 5. The distribution of image probability density [5] 
Advantages of typical morphological operations include small details elimination and the figure edge smoothing, the division of adjoining areas (Figure 6b); closing of small holes and narrow bays, linking the adjoining areas (Figure 6c); filling the narrow

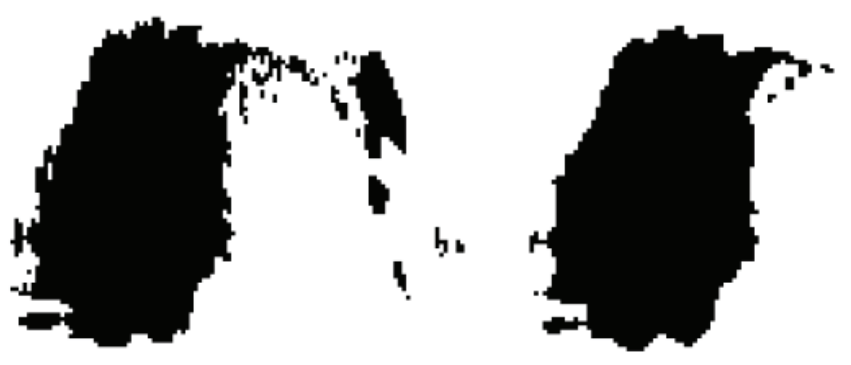

a)

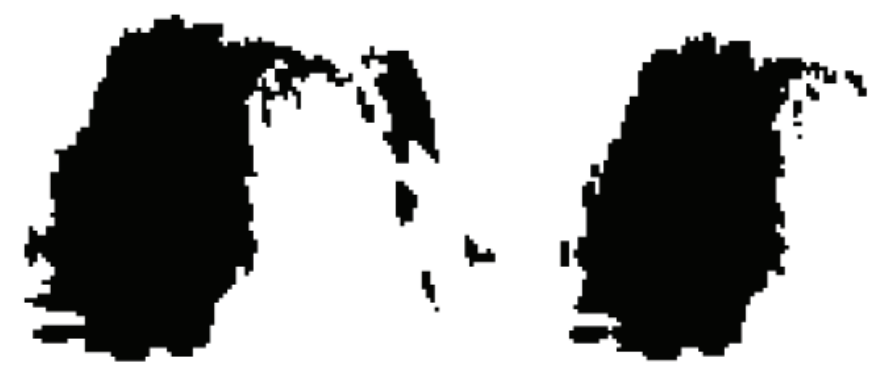

d)
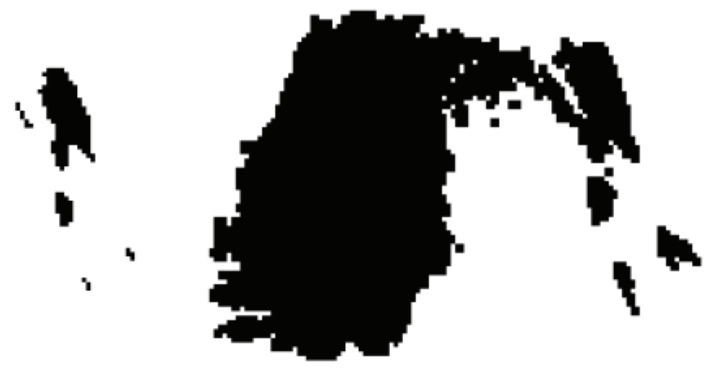

b)
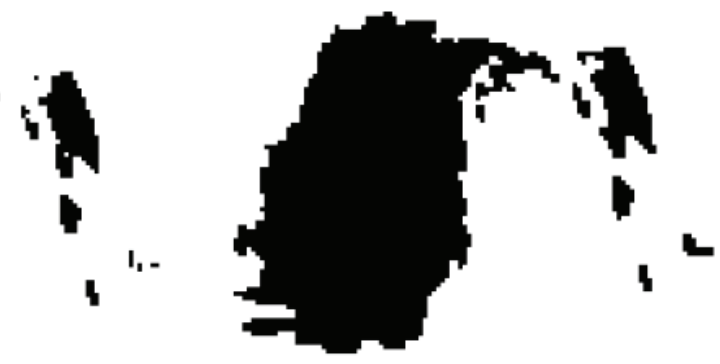

e) c)

Figure 6. Morphological transformations in the copyright MagFABRIC software, typical: (a) segmentation, (b) erosion, (c) dilatation, (d) closing operation - dilation + erosion, (e) opening operation - erosion + dilation, and (f) opening and closing operation

Table 5. Algorithms (a)-(u) tested in the experiment to obtain the optimal preprocessing algorithm.

\begin{tabular}{|c|c|c|c|c|c|}
\hline Set & \multicolumn{5}{|c|}{ Preprocessing methods } \\
\hline No. & 1. & \multicolumn{2}{|l|}{ 2. Image quality improvement } & \multicolumn{2}{|r|}{ 3. Segmentation } \\
\hline 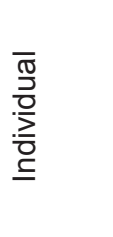 & \multirow{5}{*}{ 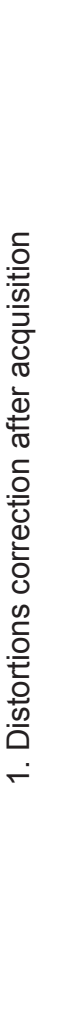 } & $\begin{array}{l}\text { (a) without; } \\
\text { (b) (h }[0-255]) ; \\
\text { (c) }\left(x^{2}\right) \\
\text { (d) }\left(x^{3}\right) \\
\text { (e) }(\text { dp G } 3 \times 3) \text {; } \\
\text { (f) }(\text { dp G } 5 \times 5) \text {; }\end{array}$ & \multirow{5}{*}{ 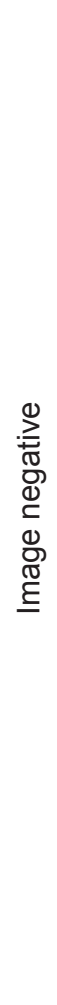 } & \multirow{5}{*}{ 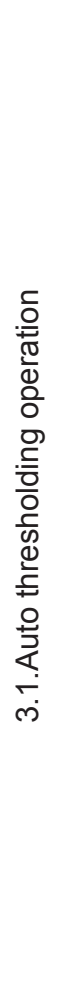 } & $\begin{array}{c}\text { 3.2 Morphological operation } \\
\text { closing }=1 x \text { dilatation }+1 x \text { erosion } \\
\text { opening }=1 x \text { erosion }+1 x \text { dilatation }\end{array}$ \\
\hline $\begin{array}{l}\dot{\bar{\pi}} \\
\dot{\bar{D}}\end{array}$ & & 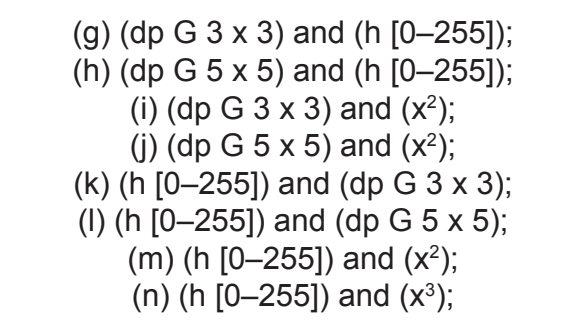 & & & \\
\hline$\frac{\ddot{0}}{i \frac{2}{2}}$ & & $\begin{array}{l}\text { (o) }(\mathrm{dp} \mathrm{G} 3 \times 3) \text { and }(\mathrm{h}[0-255]) \text { and }\left(\mathrm{x}^{2}\right) \text {; } \\
\text { (p) }(\mathrm{dp} \mathrm{G} 3 \times 3) \text { and }(\mathrm{h}[0-255]) \text {, and }\left(\mathrm{x}^{3}\right) \text {; } \\
\text { (r) }(\mathrm{dp} \mathrm{G} 5 \times 5) \text { and }(\mathrm{h}[0-255]) \text { and }\left(\mathrm{x}^{2}\right) \text {; } \\
\text { (s) }(\mathrm{dp} \mathrm{G} 5 \times 5) \text { and }(\mathrm{h}[0-255]) \text { and }\left(\mathrm{x}^{3}\right)\end{array}$ & & & \\
\hline \multirow{2}{*}{ 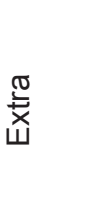 } & & (t) $(\mathrm{dp} G 3 \times 3)$ and $(\mathrm{h}[0-255])$ and $\left(\mathrm{x}^{2}\right)$ & & & $\begin{array}{l}\text { closing }=1 x \text { dilatation }+2 x \text { erosion } \\
\text { opening }=1 x \text { erosion }+2 x \text { dilatation }\end{array}$ \\
\hline & & (u) $(\mathrm{dp} \mathrm{G} 3 \times 3)$ and (h [0-255]) and $\left(\mathrm{x}^{2}\right)$ & & & $\begin{array}{l}\text { closing }=2 x \text { dilatation }+2 x \text { erosion } \\
\text { opening }=2 x \text { erosion }+2 x \text { dilatation }\end{array}$ \\
\hline
\end{tabular}


indentations and holes, linking the objects in contact (Figure $6 \mathrm{~d}$ ); fine edgings and peninsulas removal and objects in contact disconnection (Figure 6e). Besides many advantages, there is a common disadvantage with these operations - the distortion of the object resulting from a reduction or enlargement. The opening and closing operations (Figure 6f) provide a good solution to that problem.

\section{Experiment}

The aim of the experiment is to determine the optimal preprocessing algorithm. The image is preprocessed according to various algorithms contained in Figure 8 and Table 5. Then ITP structural analysis: the size, shape, and position of ITP are performed in the identification and description stages. The algorithm selection criterion is the ITP detection in the image of the fabric and the identification of the boundary line in individual ITP. The ITP detection defined as a percentage of the ITP number identified by digital image analysis, compared to the actual ITP number in the fabric, using the number of warp and weft threads, acc. formula (10).

ITP Detection [\%]-percentage of the ITP detection in the image

ITP detection $=\frac{\operatorname{ITP}_{n}}{a *(b-1)} * 100,[\%]$,

where

ITP $n$-the number of every individual ITP in image, detected by software MagFABRIC,

$a, b$-number of threads ( $a$ (warp) and $b($ weft $))$ in image.

The second criterion is the precision of ITP area boundary line detection which is assessed on the basis of the factor developed by the author defined as RID, acc. formula (11). The RID factor-allows for determining the smallest difference between the ITP real area and the ITP model area defined as AIDE. The AIDE area model is shown on Figure 7 and is

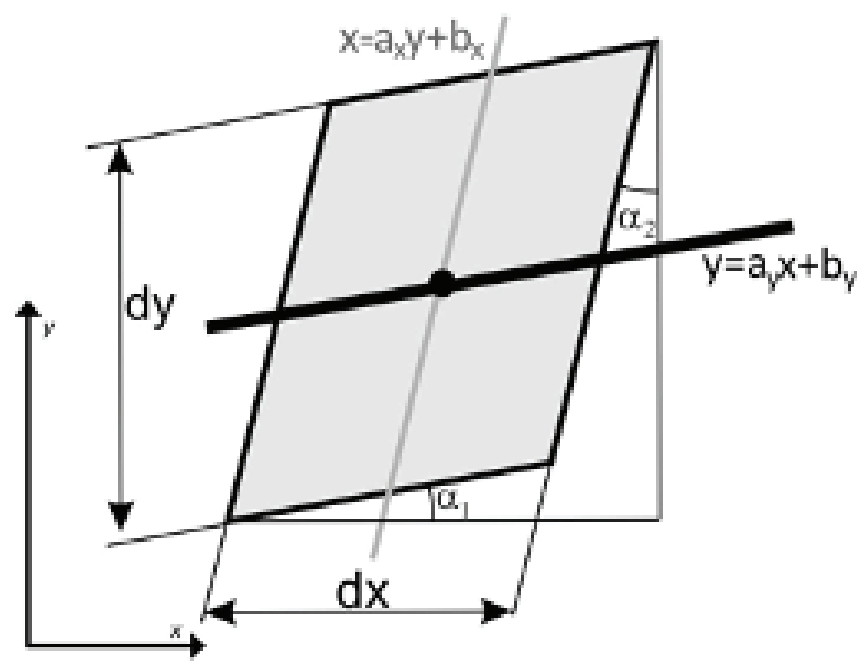

Figure 7. Graphic visualization of the AIDE model calculated from the size, shape and ITP position parameters (acc. formula 12, 13).

$\underline{\text { RID }}$-the difference between the real and model areas of the object.

$\mathrm{RID}=\mathrm{AIDE}-A,\left[\mathrm{~mm}^{2}\right]$,

where

A [ $\left.\mathrm{mm}^{2}\right]$-ITP area-the sum of pixels in the ITP, converted to $\mathrm{mm}^{2}$

AIDE-model of object area, calculated from average parameters of area, shape, and location

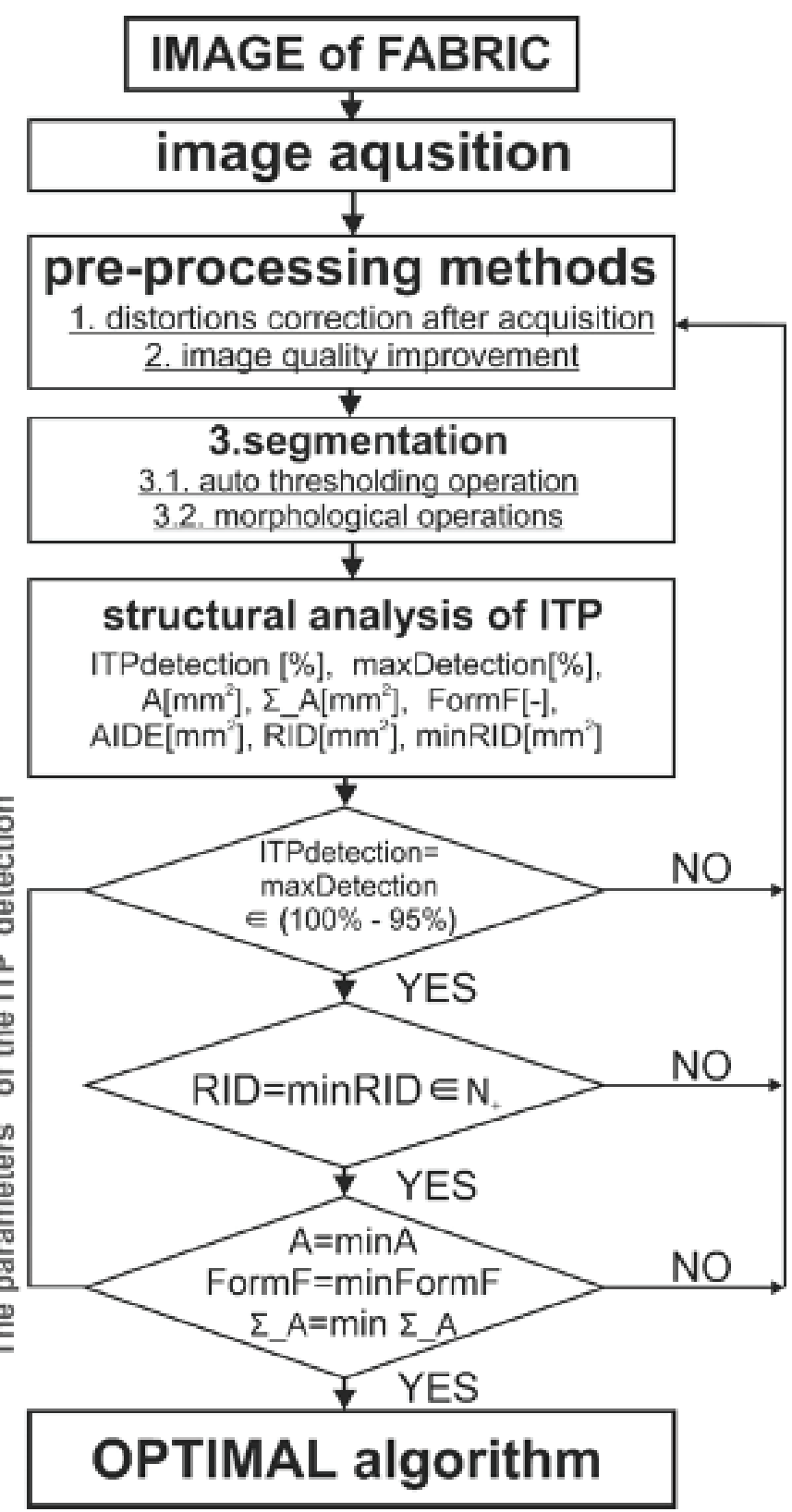

Figure 8. Algorithm of experiment procedure to optimize the algorithm of preprocessing 


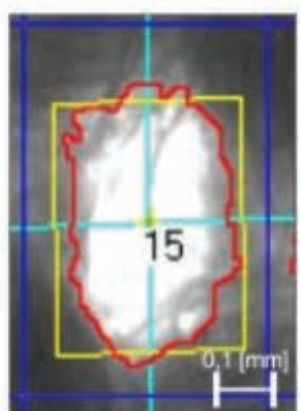

a)

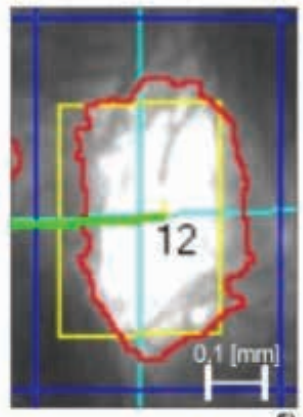

f)

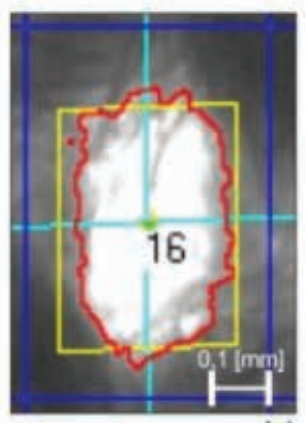

k)

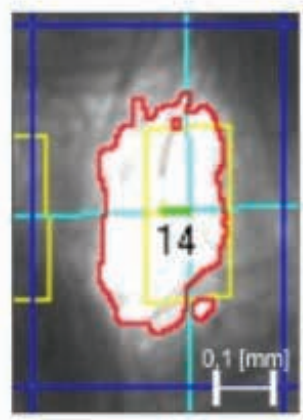

p)

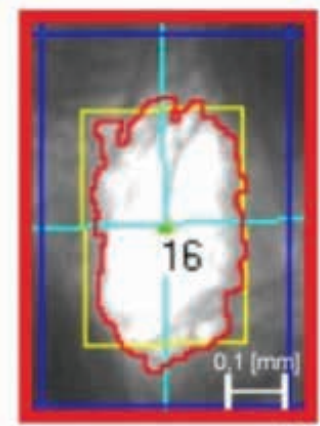

b)

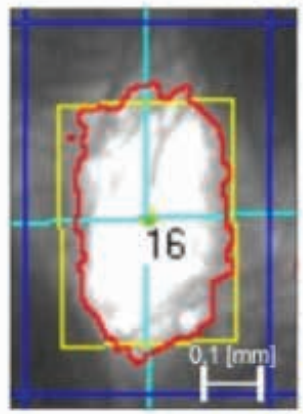

g)

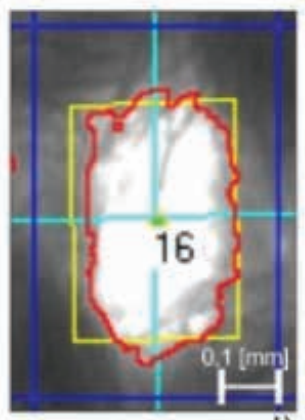

I)

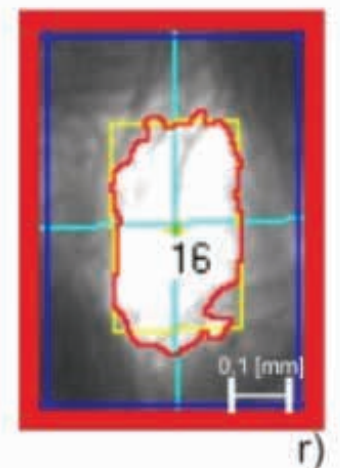

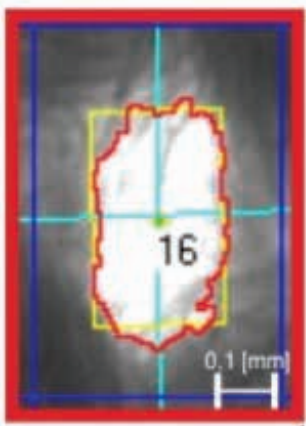

c)

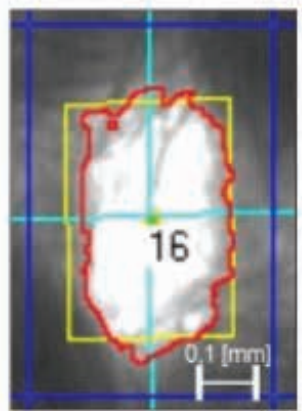

h)

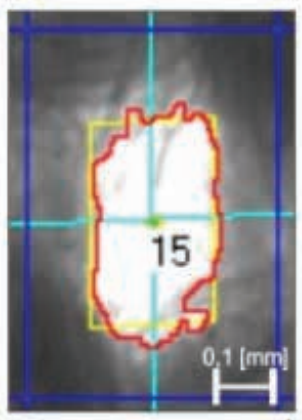

m)

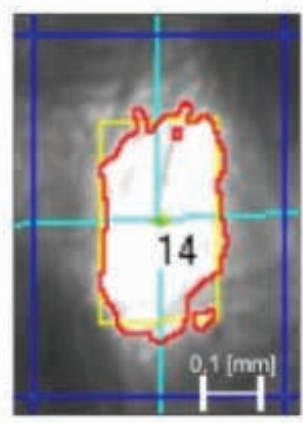

s)
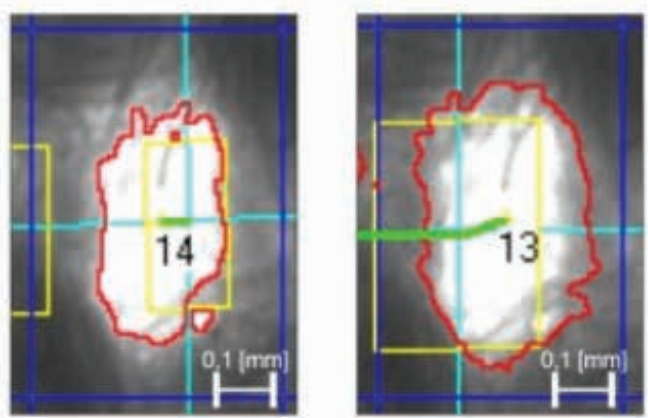

d)

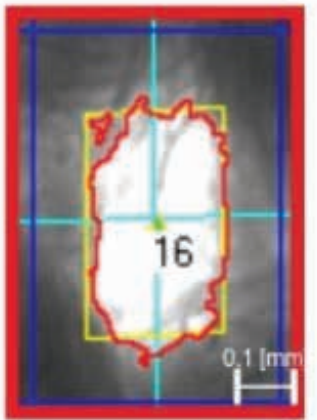

i)
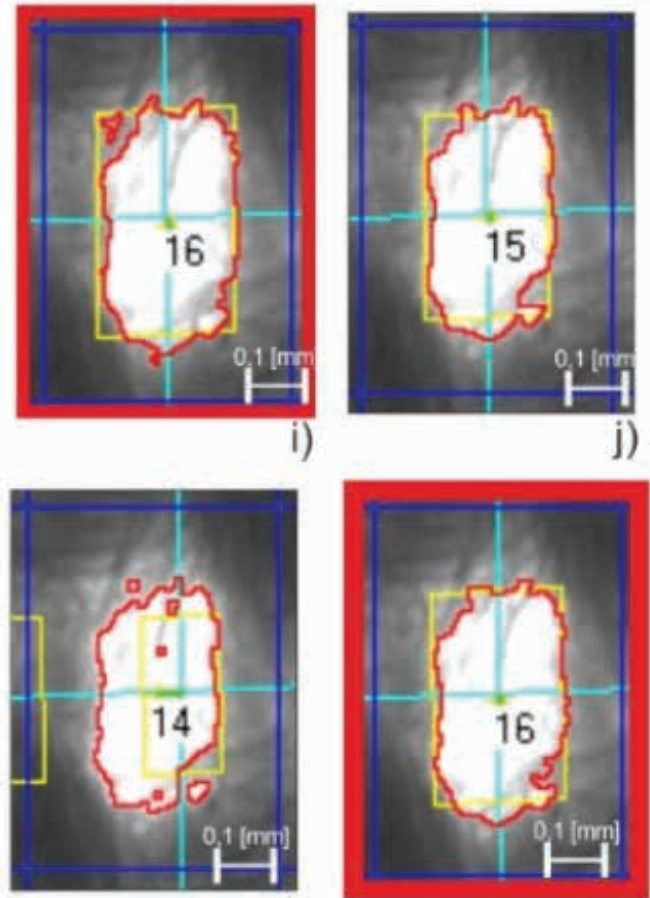

n)

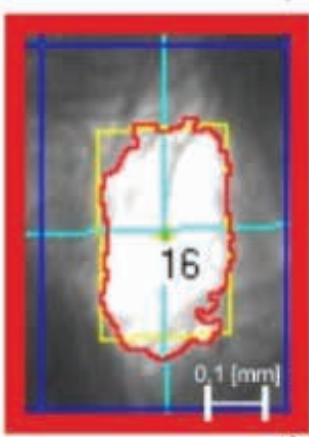

t) e)

Figure 9. The visualization of the boarding line chosen ITP in the image as the result of algorithm processing for plain weave: from (a) to (u) setting aq. to Table 4

$$
\operatorname{AIDE}=A(d x, d y),[\mathrm{pix}] \text { or }\left[\mathrm{mm}^{2}\right],
$$

where

$d x=\sqrt{\frac{\bar{A}}{1+\operatorname{tg}^{2} \alpha_{1}}}\left(1-\operatorname{tg} \alpha_{1} \operatorname{tg} \alpha_{2}\right) ; \quad d y=\frac{\bar{A} \cdot\left(1+\operatorname{tg}^{2} \alpha_{1}\right)}{\sqrt{\frac{\bar{A}}{\text { Feret }}\left(1+\operatorname{tg}^{2} \alpha_{1}\right)}} ;(13)$

$\bar{A}_{-}$- average of ITP area
Feret - ITP shape factor - the degree of object area extension, the ratio of height to the width of the ITP area: $(0 \leq$ Feret $<1)$ horizontal, (Feret $\approx 1)$ square, $(1<$ Feret $<\infty)$ vertical,

$\alpha_{1}, \alpha_{2}$ - ITP grid inclination angles,

$\operatorname{tg} \alpha_{1}, \alpha_{2}-$ trigonometric tangent function of angles $\alpha_{1}, \alpha_{2}$.

FormF $[-]$ - shape factor of the ITP area folding 

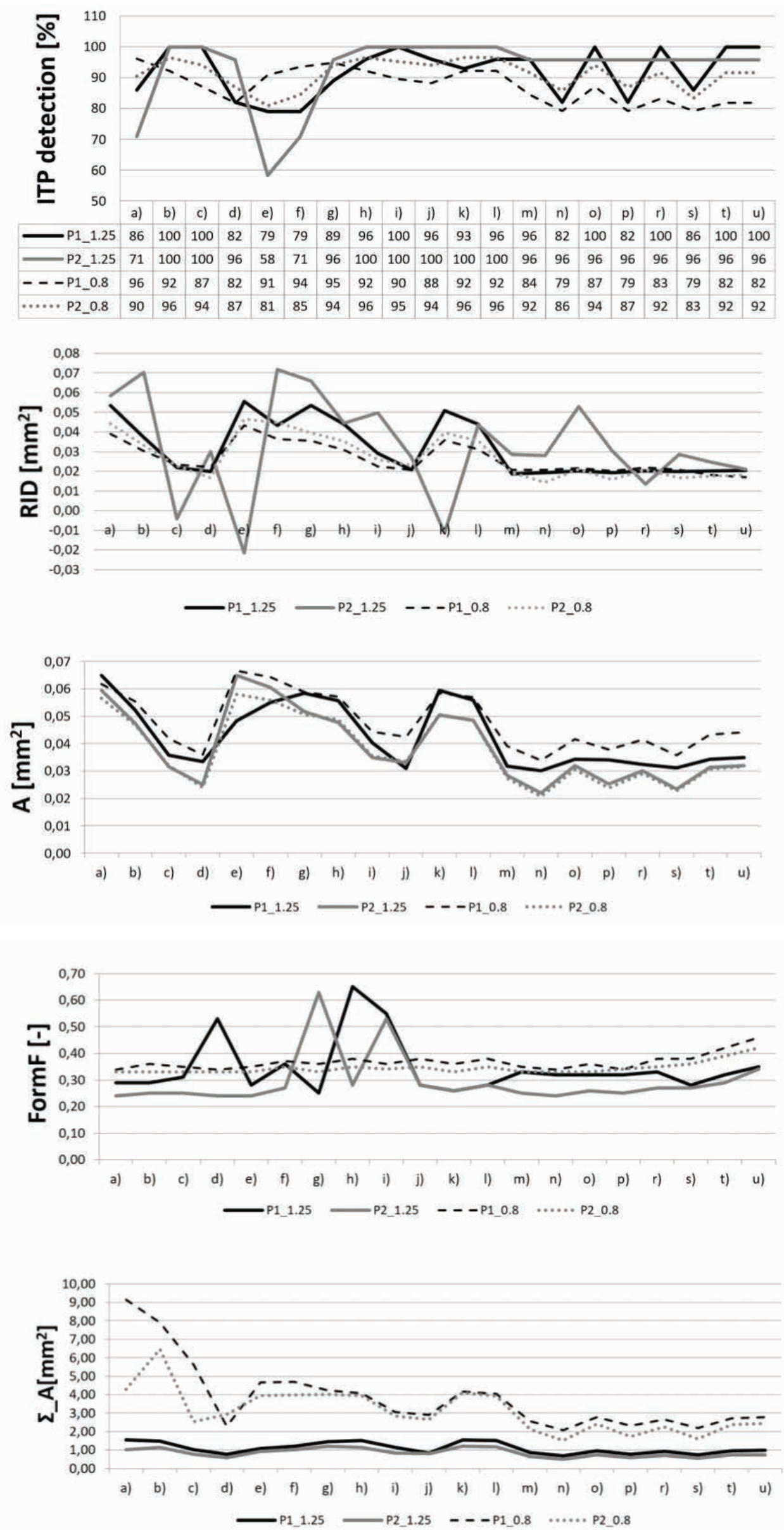

Figure 10. The result of algorithm processing for fabrics $P 1, P 2$ from (a) to (u) setting aq. to Table 5, in two magnification 1.25 and 0.8: (a) ITP Detection [\%]. (b) RID factor [rmm²]. (c) ITP A [mm2]. ITP FormF [-] 

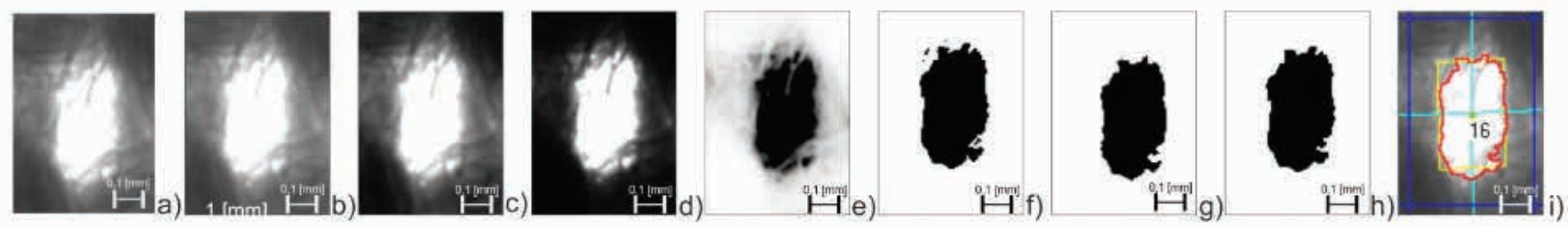

Figure 11. The image analysis of optimal algorithm of tested fabrics with plain weaves focus on the ITP: (a) the picture after the acquisition, (b) low-pass filtering 5' 5 Gaussian filter, (c) histogram equalization to the full range $\mathrm{h}[0-255]$, (d) nonlinear filtration by square filter ( $\left.\mathrm{x}^{2}\right)$, (e) image negative, (f) thresholding operation with auto threshold set by copyright procedure, (g) closing operation ( $1^{\prime}$ dilatation $1^{\prime}$ erosion), (h) opening operation (1' erosion 1' dilatation), and (i) ITP structural analysis.

Table 6. The results of algorithm processing for P1_1.25: from $(p-a)$ to $(p-u)$ setting aq. to Table 5

\begin{tabular}{|c|c|c|c|c|c|c|c|c|c|c|}
\hline $\begin{array}{c}\text { Pre- } \\
\text { processing }\end{array}$ & $\begin{array}{c}\text { Detection } \\
\text { [\%] }\end{array}$ & $\begin{array}{c}\mathrm{CV}_{-} \\
\text {Detection } \\
{[\%]}\end{array}$ & $\begin{array}{c}\text { RID } \\
{\left[\mathrm{mm}^{2}\right]}\end{array}$ & $\begin{array}{l}\text { S_RID } \\
{\left[\mathrm{mm}^{2}\right]}\end{array}$ & $\underset{[\%]}{c V_{[\%} R I D}$ & FormF[-] & $A\left[\mathrm{~mm}^{2}\right]$ & $\underset{\left[\mathrm{mm}^{2}\right]}{\mathbf{S}] \mathbf{A}}$ & $\begin{array}{c}\text { cV_A } \\
{[\%]}\end{array}$ & $\underset{\left[\mathrm{mm}^{2}\right]}{\text { S_A }}$ \\
\hline (a) & 86 & 57 & 0.054 & 0.035 & 65 & 0.29 & 0.065 & 0.037 & 57 & 1.561 \\
\hline (b) & 100 & 64 & 0.037 & 0.028 & 75 & 0.29 & 0.052 & 0.033 & 64 & 1.466 \\
\hline (c) & 100 & 83 & 0.022 & 0.021 & 95 & 0.31 & 0.036 & 0.030 & 83 & 1.002 \\
\hline (d) & 82 & 76 & 0.020 & 0.019 & 96 & 0.53 & 0.034 & 0.026 & 76 & 0.771 \\
\hline (e) & 79 & 92 & 0.056 & 0.034 & 61 & 0.28 & 0.048 & 0.044 & 92 & 1.064 \\
\hline (f) & 79 & 76 & 0.043 & 0.030 & 70 & 0.36 & 0.055 & 0.042 & 76 & 1.211 \\
\hline (g) & 89 & 56 & 0.054 & 0.031 & 59 & 0.25 & 0.058 & 0.033 & 56 & 1.461 \\
\hline (h) & 96 & 60 & 0.044 & 0.030 & 67 & 0.65 & 0.056 & 0.033 & 60 & 1.507 \\
\hline (i) & 100 & 76 & 0.029 & 0.024 & 82 & 0.55 & 0.040 & 0.031 & 76 & 1.134 \\
\hline (j) & 96 & 89 & 0.021 & 0.019 & 93 & 0.28 & 0.031 & 0.027 & 89 & 0.834 \\
\hline (k) & 93 & 57 & 0.051 & 0.032 & 63 & 0.26 & 0.060 & 0.034 & 57 & 1.548 \\
\hline (I) & 96 & 60 & 0.044 & 0.030 & 67 & 0.28 & 0.056 & 0.033 & 60 & 1.508 \\
\hline$(\mathrm{m})$ & 96 & 87 & 0.019 & 0.019 & 102 & 0.33 & 0.032 & 0.028 & 87 & 0.857 \\
\hline (n) & 82 & 80 & 0.019 & 0.018 & 93 & 0.32 & 0.030 & 0.024 & 80 & 0.695 \\
\hline (으) & $\underline{100}$ & $\underline{85}$ & $\underline{0.020}$ & $\underline{0.020}$ & $\underline{100}$ & $\underline{0.32}$ & $\underline{0.034}$ & $\underline{0.029}$ & $\underline{85}$ & $\underline{0.960}$ \\
\hline (p) & 82 & 76 & 0.019 & 0.019 & 98 & 0.32 & 0.034 & 0.026 & 76 & 0.783 \\
\hline$(\underline{r})$ & $\underline{100}$ & $\underline{89}$ & $\underline{0.020}$ & $\underline{0.019}$ & $\underline{92}$ & $\underline{0.33}$ & $\underline{0.032}$ & $\underline{0.029}$ & $\underline{89}$ & $\underline{0.907}$ \\
\hline (s) & 86 & 81 & 0.020 & 0.020 & 99 & 0.28 & 0.031 & 0.025 & 81 & 0.750 \\
\hline (t) & 100 & $\underline{85}$ & $\underline{0.020}$ & $\underline{0.020}$ & $\underline{100}$ & $\underline{0.32}$ & $\underline{0.034}$ & $\underline{0.029}$ & $\underline{85}$ & $\underline{0.960}$ \\
\hline (u) & $\underline{100}$ & $\underline{84}$ & $\underline{0.021}$ & $\underline{0.020}$ & $\underline{99}$ & $\underline{0.35}$ & $\underline{0.035}$ & $\underline{0.030}$ & $\underline{84}$ & $\underline{0.980}$ \\
\hline
\end{tabular}

Form $F=\frac{4 \pi \cdot A}{L^{2}},[-]$

where

A [mm²] - ITP area, every individual ITP area,

$L\left[\mathrm{~mm}^{2}\right]$ - the circumference of every individual ITP,
$(0 \leq F o r m F<1)$ undulating $s_{m}^{m} ;($ FormF $\approx 1)$ not undulating $\bigcirc$.

The algorithm of the experiment procedure for extracting optimal algorithm of preprocessing is shown below (Figure 8 and Table 5). 


\section{Results and Discussion}

The results of this experiment are presented in Table 6 and Figures 9 and 10. The experiment was carried out in two stages using two parameters proposed by the author: (1) ITP Detection [\%] and (2) RID factor [ $\left.\mathrm{mm}^{2}\right]$ (precision of designated ITP_a difference of the real and model areas of the ITP) and also the minimum value of size and shape of the ITP.

In the first criterion-ITP Detection [\%] and range [100-96\%], better detection is obtained with photos with 1.25 zoom than with 0.8 zoom. With $0.8 \mathrm{zoom}$, there was no value for $100 \%$ detection for all algorithms and for $96 \%$ only for the algorithm (a), (b), (h), (k), (l). For fabric P1_1.25, it is difficult to analyze due to its irregular structure and invisible ITP, and in algorithms (b), (c), (i), (o), (r), (t), (u) 100\% ITP detection was achieved. For P2_1.25 fabric which has a more regular structure and the condition [100-96\%] is met by algorithms from $(g)$ to $(u)$.

In the second selection criterion-RID $\left[\mathrm{mm}^{2}\right]$ and range minimum, the precision of ITP detection-the smallest value of the RID coefficient occurred in cases $(0),(r),(t),(u)$. The ITP area in these cases is also the lowest, FormF coefficient. The visual effect of the ITP boundary line (Figure 9) and value of ITP area (Table 6 and Figure 10) in cases (b), and (i) indicate that the ITP area is too large $(0.04-0.05[\mathrm{~mm}])$.

For the optimal preprocessing algorithm the case of $(r)$ can be adopted due to the smallest values of RID, A, $\Sigma_{-}$A and FormF. These results confirm the visual effect of the determination of the boundary line in individual ITP, which smoothly shapes the ITP, considering the hairiness of the threads. In other cases, $(\mathrm{o}),(\mathrm{t}),(\mathrm{u})$, we see too much rippling of the boundary line, outlining a much larger ITP area. The visual assessment is compatible with quantitative results. Taking into account the results of the optimal preprocessing algorithm for plain weave fabric with variant $(r)$ is presented in Figure 11. The optimal algorithm should be composed of low-pass filtering (dp G $5 \times 5$ ), histogram equalization to the full range $h[0-255]$ and nonlinear filtration through a square filter $\left(x^{2}\right)$ and single morphological operations. The morphological operations allow the shoreline to be maintained according to the hairiness of the thread (single operations).

\section{Conclusions}

The aim of this article was to choose the optimal preprocessing algorithm for a fabric structure with a plain weave and present the most important problems related to the initial stage of the fabric computer image analysis. The implementation of the new optimal algorithm results from the new methodology of individual ITP examination.

At the stage of image acquisition, the following parameters were determined: the irregularity of the image of the fabric and the presence of radiometric and geometrical deformations by through developed methods. For the optimal algorithm, selection was determined by the author's criteria (ITP Detection and RID coefficient and minimum of size and shape of the
ITP). The result of structural analysis of ITP with the prescribed parameters show convergence with the visual effect in the form of the ITP boundary line in the range of the individual ITP field.

This experiment represents a new approach to this type of analysis. It focuses on each individual ITP and the precision of determining the ITP boundary line, but not the general information about the area of all ITP. The limitation of this method may be the fabric structure with invisible ITP (e.g., for a satin weave). The validity of the problem is presented on the basis of tests of the air permeability of two structurally differentiated fabrics in relation to the value of structural parameters of ITP in the image of plain-woven fabric. The above issues are crucial when assessing the properties of structures that must be an effective barrier: air permeability; flow resistance; UV radiation; viruses penetration e.g. HIV, HBV, HCV; as well as specialized fabrics (e.g. industrial filters, composites and others). This article is an integral part of the research carried out in the area of morphometric analysis of a single ITP in the fabric structure [13].

\section{Funding}

This research received no specific grant from any funding agency or from the public, commercial, or nonprofit sectors.

\section{References}

[1] Kang, T. J., Choi, S. H., Kim, S. M. (2001). Automatic structure analysis and objective evaluation of woven fabric using image analysis. Textile Research Journal, 71(3), 261-270.

[2] Zupin, Z., Hladnik, A., Dimitrovski, K. (2011). Prediction of one-liner woven fabric air permeability using porosity parameters. Textile Research Journal, 82(2), 117-128.

[3] Turan, R. B., Okur, A. (2012). Investigation of pore parameters of woven fabrics by theoretical and image analysis methods. Journal of the Textile Institute, 103(8), 875-884.

[4] Polipowski, M., Wiecek, P., Wiecek, B., Pinar, A. (2017). Influence of selected parameters of the channels between threads on the air permeability of flat textile products with known characteristics. Fibres and Textiles in Eastern Europe, 25, 129-138.

[5] Polipowski, M., Wiecek, P., Wiecek, B., Pinar, A. (2017). Analysis of the effect of channel parameters between filaments and single fabric parameters on air permeability. Water vapour resistance and thermal resistance. Fibres and Textiles in Eastern Europe, 25, 79-86.

[6] Gooijer, H., Warmoeskerken, M. M. C. G., Groot Wassink, J. (2003). Flow resistance of textile materials. Part I: Monofilament fabrics. Textile Research Journal, 73(5), 437-443.

[7] Swery, E. E., Allen, T., Kelly, P. (2016). Automated tool to determine geometric measurements of woven textile using digital image analysis techniques. Textile Research Journal, 86(6), 618-635.

[8] Dulęba-Majek, M. (2009). Transmission of UV radiation through woven fabric in dependence on the inter-thread spaces. Fibres and Textiles in Eastern Europe, 17(2), 3438. 
[9] Dal, V., Atmaca, M., Yildiz, Z., Ceviz, N. O., Hes, L. (2016). Thermal comfort of woolen fabrics depending on physical properties. Journal of Natural Fibers, 13(6), 714-725.

[10] Dubrovski. P. D., Brezocnik, M. (2002). Using genetic programming to predict the macroporosity of woven cotton fabrics. Textile Research Journal, 72(3), 187-194.

[11] Tàpias, M., Ralló, M., Escofet, J., Algaba, I., Riva, A. (2010). Objective measure of woven fabric's cover factor by image processing. Textile Research Journal, 80(1), 3544.

[12] Tapias, M., Rallo, M., Escofet, J. (2011). Automatic measurements of partial cover factors and yarn diameter in fabrics using image processing. Textile Research Journal, 81(2), 173-186.

[13] Owczarek, M. (2019). Morphometrical structural analysis of inter-thread pores in woven fabrics with the use of computer image analysis. Textile Research Journal, 89(2324), 4858-4874.

[14] Ohta, K., Sakaue, K., Tamura, H. (1986). Pattern recognition of fabric surfaces. Journal of the Textile Machinery Society of Japan, 32(1), 7-10.

[15] Owczarek, M., Masajtis, J. (2002, October/December). Influence of initial image preparation on the result of the image digital analysis. Fibres \& Textiles in Eastern Europe, 10(4), 31-32.

[16] Windyga, P. S. (2001). Fast impulsive noise removal. IEEE Transactions on Image Processing, 10, 173-179.

[17] Chang, C. C., Hsiao, J. Y., Hsieh, C. P. (2008). An adaptive median filter for image denoising. In: Second International Symposium on Intelligent Information Technology Application. Shanghai. China. 20-22 December 2008. Vol. 2, 346-350. Washington. DC: IEEE.
[18] Ibrahim, H., Kong, N. S. P. (2007). Brightness preserving dynamic histogram equalization for image contrast enhancement. IEEE Transactions on Consumer Electronics, 53, 1752-1758.

[19] Materka, A. (1991). Elements of digital image processing and analysis. Elementy cyfrowego przetwarzania $i$ analizy obrazów. PWN Warszawa (Łódź). ISBN:83-01-10566-6 (in Polish).

[20] Tadeusiewicz, R., Korohoda, P. (1997). Computer image analysis and processing. Komputerowa analiza $i$ przetwarzanie obrazów. FPT Kraków. ISBN:83-86476$15-X$ (in Polish).

[21] Bovik, A. (2000). Handbook of image \& video processing. Academic Press (USA). ISBN:0-12-119790-5.

[22] Gonzalez, R. C., Wood, R. E. (2008). Digital image processing. Pearson Education (NJ). ISBN:0-13-168728-X.

[23] Sankowski, D., Mosorov, V., Strzecha, K. (2011). Processing and image analysis in industrial systems. Przetwarzanie $i$ analiza obrazów w systemach przemysłowych. PWN. ISBN:978-83-01-16571-0 (in Polish).

[24] Stapor, K. (2011). Methods of objects classification in computer vision. Metody klasyfikacji obiektów w wizji komputerowej. PWN. ISBN:978-83-01-16581-9 (in Polish).

[25] Owczarek, M., Masajtis, J. (2006). Evaluation of the Jeans fabric structure homogeneity by means of digital image analysis. Fibres \& Textiles in Eastern Europe, 14(2), 41-45.

[26] Kinoshita, M., Hashimoto, Y., Akiyama, R., Uchiyama, S. (1989). Determination of weave type in woven fabric by digital image processing. Journal of the Textile Machinery Society of Japan, 35(2), 1-4.

[27] Kuo. F. J., Shih, Y., Huang, C., Su, T.-L., Liao, C. (2016). A novel image processing technology for recognizing the weave of fabrics. Text Research Journal, 86(3), 288-301. 